\title{
Occurrence and Distribution of Multiple Antibiotic Resistance Bacteria of Public Health Significance in Backwaters and Aquaculture Farm
}

\author{
Hemanta Pokhrel ${ }^{1}$, Sangipran Baishya ${ }^{1}$, Bipul Phukan', \\ Devika Pillai ${ }^{2}$ and Mohd Ashraf Rather ${ }^{3 *}$ \\ ${ }^{1}$ College of Fisheries Science, AAU, Raha, Nagaon- Assam, India \\ ${ }^{2}$ School of Aquaculture and Biotechnology, Kerala University of Fisheries and \\ Ocean Studies, India \\ ${ }^{3}$ College of Fisheries, Ratnagiri, Maharashtra, India
}

*Corresponding author

\begin{tabular}{|l|}
\hline K e y w o r d s \\
$\begin{array}{l}\text { Antibiotic resistance, } \\
\text { Antimicrobials, } \\
\text { Antibiotic resistance } \\
\text { index, Multiple } \\
\text { antibiotic resistance }\end{array}$ \\
\hline Article Info \\
\hline $\begin{array}{l}\text { Accepted: } \\
\text { 10 January } 2018 \\
\text { Available Online: } \\
\text { 10 February } 2018\end{array}$ \\
\hline
\end{tabular}

\section{Introduction}

Development and spread of antimicrobial resistance have become a global public health problem, impacted by both human and nonhuman antimicrobial usage (Rigos et al., 2010). It is generally acknowledged that any use of antimicrobial agents can lead to the emergence of antimicrobial resistant microorganisms and further promote the
Resistance to antimicrobial agents among clinically important pathogens in the community and environment has compromised therapy and requires constant monitoring of emerging pathogens. Current investigation was aimed at determining the antimicrobial resistance pattern in bacteria isolated from public water body near a hospital and also from two fish farms which used the same water for aquaculture. Of 105 isolates, maximum number of isolates belonged to the Enterobacter spp. Multiple antibiotic resistance (MAR), i.e. resistance to more than two antibiotics, occurred in almost $100 \%$ of Enterobacter spp. and Streptococcus spp. Of the total 105 isolates, only $6.66 \%$ were susceptible to all the antibiotics. Of the $93.33 \%$ isolates, $6.1 \%$ were resistant to three antibiotics, $44.89 \%$ were resistant to 4 to 10 antibiotics $48.97 \%$ were resistant to more than 10 antibiotics. Most strains exhibited multi drug resistant character and all the isolates had a very high MARindex, suggesting the origin of the isolates is from an area highly contaminated with antibiotics. Antibiotic resistance indices were found to be highest for Enterobacter spp followed by Streptococcus spp and lowest for Vibrio and Aeromonas group. The results highlight a much higher risk of spreading of MAR from terrestrial environment to aquatic environment which will distinctly affect aquaculture production. 
to another country, for instance, through export/import of food items including fish and fishery products. Antimicrobial resistance deriving from the usage of antimicrobials in aquaculture presents a risk to public health.

Development of acquired resistance in bacteria in aquatic environments that can infect humans. This can be regarded as a direct spread of resistance from aquatic environments to humans. Development of acquired resistance in bacteria in aquatic environments whereby such resistant bacteria can act as a reservoir of resistance genes from which the genes can be further disseminated and ultimately end up as human pathogens. This can be viewed as an indirect spread of resistance from aquatic environments to humans caused by horizontal gene transfer.

Intensive aquaculture (shrimp and fish farming) has also led to growing problems with bacterial diseases, the treatment of which very often requires the intensive use of antimicrobials. These include disinfectants (e.g., hydrogen peroxide and malachite green), antibiotics (e.g. sulfonamides and tetracyclines) and anthelminthic agents (e.g. pyrethroid insecticides and avermectins) (Rawn et al., 2009). Frequent use of antimicrobials leads to the development of resistance in bacteria as a natural survival mechanism. Antimicrobial resistance (AMR) is the "resistance of a microorganism to an antimicrobial medicine to which it was previously sensitive. Standard treatments become ineffective and infections persist and may spread to others."(WHO, 2012).

As existing antimicrobial agents decline in effectiveness, infections will be more difficult and expensive to treat and epidemics harder to control. The environmental consequences of the widespread use of antimicrobial agents are still little understood. The medical community, governments, the World Health
Organization, and other nongovernmental international agencies have begun to institute policies to address the problem of antimicrobial resistance. Thus this study was undertaken to understand the nature of increasing antimicrobial resistance in bacteria in water bodies and in aquaculture fish farm from these water bodies. The objectives of the present investigation were: to assess the susceptibility of isolates from different water bodies to various antibiotics and to determine the Antibiotic Resistance Index (ARI) and Multiple Antibiotic Resistance index (MAR).

\section{Materials and Methods}

\section{Description of the site}

Water, soil and fish samples were collected from water bodies and aquaculture farms in the Panangad region $\left(\mathrm{N} 09^{\circ}\right.$ 54. 828') (E 076 19. 501') of Vembanad backwaters of Kerala. Different samplings sites are indicated in the map as per the location in Figure 1. The figure suggest that the study area is comprises of two stations. Station 1 comprises of lakeshore area $\left(\mathrm{L}_{1}\right)$ and station 2 comprises of farm $1\left(\mathrm{~F}_{1}\right)$ and farm $2\left(\mathrm{~F}_{2}\right)$.

\section{Sample collection}

Three Samples of each water, soil and fish were collected from four different stations. Samples for microbial analysis were collected from surface and bottom using standard protocol and were aseptically transferred into sterile glass bottles and transported to the laboratory through ice box and was processed with 2 hours. Analysis was performed in duplicated for each stations.

\section{Biochemical charaterisation}

The purified samples were allowed to grown in Nutrient broth for $18 \mathrm{hr}$ and the $\mathrm{n}$ the isolates were used for further biochemical 
confirmation. Purified isolates were subject to a series of 13 biochemical and 21 sugar test for the identification and differentiation. Further morphological morphological and biochemical properties were also studied according to Bergey's manual of determinative bacteriology for identification of isolates.

\section{Antibiotic sensitivity testing}

Antibiotic susceptibility patterns for the various bacterial isolates were determined using commercial antibiotic disks (Hi Media, Mumbai) in accordance with the Clinical and Laboratory Standards Institute (CLSI) guidelines by Kirby-Bauer disc diffusion method (Bauer et al., 1996). A total of 18 antibiotics, viz., Ampicillin (AMP, 10 $\mu \mathrm{g}$ ), Amikacin (AK 30 $\mu$ g), Azithromycin (AZM

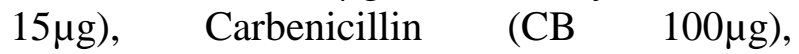
Cloramphenicol (C 30 $\mu$ g), Ciprofloxacin (CIP $5 \mu \mathrm{g})$, Cefepime (CPM 30 $\mu \mathrm{g})$, Erythromycin (E $15 \mu \mathrm{g}), \quad$ Gentamicin (GEN

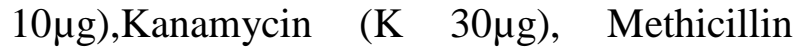

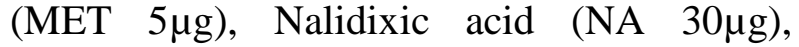

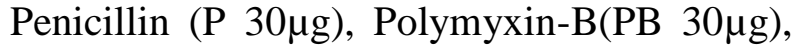

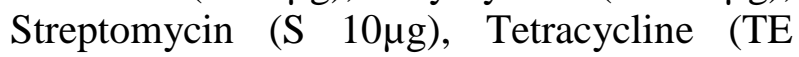
30 $\mu \mathrm{g}$ ), Trimethoprim (TR $5 \mu \mathrm{g}$ ) and

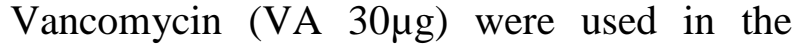
present study.

The sterile Petri plates containing $20 \mathrm{ml}$ of Muller Hinton $(\mathrm{MH})$ agar and 12-hour fresh culture of isolates were used for the study. The response of the organism to antibiotic was determined by spreading $1 \times 10^{6}$ cells per $\mathrm{ml}$ culture on $\mathrm{MH}$ agar plates.

The standardized bacterial suspension was then swab inoculated on the Muller Hinton agar using a sterile cotton swabs. An antibiotic impregnated disc of $6 \mathrm{~mm}$ diameter was used for the test. Discs were placed on the agar media with the help of a sterile forceps ensuring sufficient distance between discs.
The plates were then incubated at room temperature for 12 to 15 hours and were observed. Zones of growth inhibition were measured (CLSI, 2009). These results were used in the calculation of ARI and MAR index for total number of isolates as shown below:

\section{Antibiotic resistance pattern}

Antibacterial resistance index (ARI) of each sampling site was determined using the formula, $A R I=y / n x$, where $y$ is the actual number of resistance microbes in the sample, $\mathrm{n}$ is the population size and $\mathrm{x}$ is the total number of antibiotics tested in the sensitivity test (Hinton and Linton, 1983). Based on the occurrence of resistance to more than three antibiotics the isolates of each sampling site were also grouped as multiple antibiotic resistance isolates.

\section{Multiple Antibiotic Resistance (MAR)}

Multiple Antibiotic resistance (MAR) index was determined for isolates that showed resistance to more than three antibiotics (Krumperman, 1985).

MAR index $=\mathrm{a} / \mathrm{b}$

Where,

$\mathrm{a}$ is the number of antibiotics to which the isolate shows resistance.

$\mathrm{b}$ is the number of antibiotics to which the isolate was exposed.

MAR index value higher than 0.2 is considered to have originated from high risk sources of contamination like human, commercial poultry farms, swine and dairy cattle where antibiotics are very often used. MAR index value of less than or equal to 0.2 is considered to have originated from strains in animals in which antibiotics are seldom or never used (Krumperman, 1985). 


\section{Statistical analysis}

Mean of the antibiotic resistance pattern from different sampling sites were compared by one way analysis of variance (ANOVA) using statistical software SPSS. Multiple antibiotic resistance percentage was also calculated for all 18 different antibiotics and 10 samples using ANOVA. Post Hoc test was carried out if there was any significance difference among them.

\section{Results and Discussion}

\section{Bacterial Counts}

The distributions of microbial populations among different sampling sites are shown in Table 1. Out of 105 isolates, 101 were identified and remaining 4 which cannot be identified are listed as unknown. Maximum 18 numbers of bacterial strains were recorded from fish sample, while minimum of 6 numbers was recorded from water of each of farm and $\mathrm{L}_{1}$ area. The population of bacteria in different classes exhibited in the study are shown in figure 2. Among all the different isolates the most frequently occurring with maximum resistance in the samples were Klebsiella pneumoniae, Klebsiella oxytoca, Acinetobacter johnsonii, Enterobacter aeroginosa, Bacillus circulans and Enterococcus phoeniculicola.

\section{Biochemical characterisation}

Using the morphological as well as biochemical characteristics obtained from different biochemical tests, the isolates were identified using online software called Online Bacterial Identification software (AIBS) 2014 (http://www.tgw1916.net/bacteria_logare_des ktop.html) as well as Bergey's Manual of Systematic Bacteriology, Vol-I. Out of 100 isolates (excluding the unidentified 4 numbers), 53 are different types of bacteria which were isolated, while the remaining 48 isolates were the same as the 53 identified species.

\section{Antibiotic sensitivity test}

The antibiotic sensitivity test was determined based on the measurement of zone formation, given according to the Clinical and Laboratory Standards Institute (CLSI, 2009). The strains with no zone or with size of the zone formation less than $10 \mathrm{~mm}$ in diameter was regarded as resistant strain. On the other hand the strains is said to be sensitive when the zone formation is equal to or more than 15 $\mathrm{mm}$ in diameter, as given by the CLSI. During the study period maximum number of strains isolated from station 1 showed no zone formation. $K$. oxytoca was found to be resistant to all the 18 different antibiotic tested. K. pneumoniae and Bacillus circulans were found to be sensitive to Chloramphenicol, gentamycin, nalidixic acid and tetracycline. Other strains like Flavobacterium breve, Bacillus carbonificus and Acinetobacter calcoaceticus $\left(A_{1}\right.$ phenotype) showed slightly less resistance than the above strains. Similarly, all samples from the other station showed similar kind of resistance as observed in station 1. All the strains isolated from fish or shellfish from both the stations should $100 \%$ resistance to penicillin, methicillin and vancomycin. Bacterial strains isolated from shellfish from station 1 revealed maximum resistance to antibiotics employed in the study.

\section{Antibiotic resistance index}

Of the total 105 isolates, only $6.66 \%$ were susceptible to all the antibiotics. Of the $93.33 \%$ isolates, $6.1 \%$ were resistant to three antibiotics (cluster I), $44.89 \%$ were resistant to 4 to 10 antibiotics (cluster II), $48.97 \%$ were resistant to more than 10 antibiotics (cluster III) and a total of $93.33 \%$ exhibited Multiple 
Antibiotics Resistance (MAR). The pattern of antibiotic resistance in different isolates from different sources is represented in Table 2. In water sample, highest antibiotic resistance (>10 antibiotics) was evident in $\mathrm{L}_{1}$ and $\mathrm{F}_{2}$ followed by $F_{1}$. Similarly, multiple antibiotic resistance index was highest in soil and clam sample collected from $\mathrm{L}_{1}$ followed by $\mathrm{F}_{2}$ soil sample. Incidence of antibiotic resistance in isolates from farm samples (water, soil and fish) showed slightly lower level as that of Lakeshore samples. Thus, incidence of antibiotic resistance was higher in station 1 $\left(\mathrm{L}_{1}\right)$ when compared to that of station $2\left(\mathrm{~F}_{2}\right)$.

\section{Antibiotic wise comparison of ARI}

Percentage wise comparison of antibiotic resistance is represented in Table 3. Incidence of antibiotic resistance was evident against all the 18 different types of antibiotics used in the study.

But the highest incidence was recorded against penicillin, methicillin, vancomycin, polymyxcin and ciprofloxacin followed by ampicillin, amikacin, tetracycline and trimethoprim irrespective of the sampling site, as is shown in Table 3. However antibiotic resistance was slightly in the lower against gentamycin, azithromycin chloramphenicol, carbenicillin and erythromycin (Table 3). Bacterial strain isolated from the study area showed $100 \%$ resistance to antibiotics like penicillin, methicillin and vancomycin. Apart from this, other antibiotics like ampicillin, azithromycin, chloramphenicol, kanamycin, polymyxin B and Streptomycin showed almost $85 \%$ resistant to the isolated tested. Few antibiotics like amikacin, Ciprofloxacin, gentamycin, carbenicillin and erythromycin showed $66 \%$ resistant to all the isolates.

However, site wise comparison showed that $\mathrm{L}_{1}$ i.e in the public water body near the hospital strains like Klebsiella pneumoniae,
Klebsiella oxytoca and Bacillus circulans revealed maximum resistance to all the antibiotics. The isolates from the water sample collected from this station showed $100 \%$ resistance to penicillin, methicillin, ciprofloxacin and nalidixic acid. Among all samples within the two stations $100 \%$ resistance was observed in case of penicillin, methicillin and vancomycin.

Interestingly, more resistance was observed in fish samples rather than water and soil from the two stations in overall comparison of antibiotic resistance. In both samples of fish and shell fishes collected from the study area $100 \%$ resistance was reported in penicillin, methicillin, ciprofloxacin and vancomycin (Table 3).

\section{Class wise comparison of resistance}

Among all the classes streptococcus groups top the charts with $100 \%$ multiple antibiotic resistance (MAR) followed by Enterobacteriaceae with $93.44 \%$. Bacillus and Penaeibacillus showed $80 \%$ whereas by Pasteurellaceae and Vibrio/ Aeromonas groups showed $70 \%$ and $66.66 \%$ respectively.

Maximum susceptibility to the antibiotics was shown by the class Vibrio/Aeromonas with 33.335 susceptibility while Pasteurellaceae showed $30 \%$ and Bacillus and Penaeibacillus with $20 \%$ whereas enterobactereace showed only $6.5 \%$ susceptibility.

Among the different classes the maximum antibiotic resistance index was shown by Enterobactereacea and streptococcus groups with ARI index of 0.05 followed by Pasteurellaceae and Bacillus/Penaeibacillus with 0.04 and Vibrio/Aeromonas with 0.03 . Diagrammatic representation of MAR percentage of different samples and MAR percentage exhibited by the different classes of bacteria is shown in Figure 2, 3 and 4. 
Table.1 Distribution of bacteria belonging to different classes among stations

\begin{tabular}{|c|c|c|c|c|c|c|c|}
\hline Stations & samples & isolates & $\begin{array}{c}\text { Enterobacteri } \\
\text { aceae }\end{array}$ & Pasteurellaceae & $\begin{array}{c}\text { Vibrio and } \\
\text { Aeromonas }\end{array}$ & $\begin{array}{c}\text { Bacillus and } \\
\text { Penaeibacillus }\end{array}$ & $\begin{array}{l}\text { Strepto } \\
\text { coccus }\end{array}$ \\
\hline \multirow[t]{4}{*}{$\mathbf{L}_{1}$} & water & 6 & 4 & - & 1 & 1 & - \\
\hline & soil & 7 & 2 & 3 & - & 2 & - \\
\hline & fish & 18 & 11 & 1 & 1 & - & 3 \\
\hline & shell fish & 12 & 8 & 1 & 1 & - & 1 \\
\hline \multirow[t]{3}{*}{$\mathbf{F}_{1}$} & water & 8 & 3 & - & - & 3 & 2 \\
\hline & soil & 6 & 3 & - & 1 & 3 & - \\
\hline & fish & 12 & 4 & 1 & - & 4 & 1 \\
\hline \multirow[t]{3}{*}{$\mathbf{F}_{2}$} & water & 12 & 9 & - & 1 & 2 & - \\
\hline & soil & 10 & 8 & 2 & - & - & - \\
\hline & fish & 14 & 10 & 2 & 1 & - & 1 \\
\hline Total & 10 & 105 & 62 & 10 & 6 & 15 & 8 \\
\hline
\end{tabular}

Table.2 Antibiotic resistance pattern in various isolates from different sources

\begin{tabular}{|c|c|c|c|c|c|c|c|c|}
\hline \multirow[t]{2}{*}{$\begin{array}{l}\text { Sr. } \\
\text { No }\end{array}$} & \multirow[t]{2}{*}{$\begin{array}{c}\text { Isolate } \\
\text { sites }\end{array}$} & \multirow[t]{2}{*}{$\begin{array}{c}\text { Total } \\
\text { isolates }\end{array}$} & \multirow[t]{2}{*}{ Susceptible } & \multicolumn{3}{|c|}{$\begin{array}{c}\text { Resistant } \\
\text { Clusters }\end{array}$} & \multirow[t]{2}{*}{ MAR } & \multirow[t]{2}{*}{ ARI } \\
\hline & & & & I & II & III & & \\
\hline 1 & $\mathrm{~L}_{1}$ water & 6 & 1 & 1 & 1 & 3 & 5 & 0.05 \\
\hline 2 & $\mathrm{~L}_{1}$ soil & 7 & 0 & 0 & 2 & 5 & 7 & 0.06 \\
\hline 3 & $\mathrm{~L}_{1}$ fish & 18 & 1 & 1 & 10 & 6 & 17 & 0.05 \\
\hline 4 & $\mathrm{~L}_{1}$ clam & 12 & 0 & 0 & 7 & 5 & 12 & 0.05 \\
\hline 5 & $\mathrm{~F}_{1}$ water & 8 & 1 & 1 & 1 & 5 & 7 & 0.04 \\
\hline 6 & $\mathrm{~F}_{1}$ soil & 6 & 0 & 0 & 2 & 4 & 6 & 0.06 \\
\hline 7 & $\mathrm{~F}_{1}$ fish & 12 & 2 & 2 & 4 & 4 & 10 & 0.04 \\
\hline 8 & $\mathrm{~F}_{2}$ water & 12 & 0 & 0 & 8 & 4 & 12 & 0.06 \\
\hline 9 & $\mathrm{~F}_{2}$ soil & 10 & 0 & 0 & 3 & 7 & 10 & 0.06 \\
\hline 10 & $\mathrm{~F}_{2}$ fish & 14 & 2 & 1 & 6 & 5 & 13 & 0.05 \\
\hline
\end{tabular}

Cluster I: Contains isolates resistant to $\leq 3$ antibiotics Cluster II: Contains isolates resistant to $4-10$ antibiotics Cluster III: Contains isolates resistant to $\geq 10$ antibiotics MAR Group: Contains isolates resistant to $\geq$ three antibiotics 
Table.3 Antibiotic resistance profile (individual antibiotic wise) from different sampling sites (\%)

\begin{tabular}{|c|c|c|c|c|c|c|c|c|c|c|c|}
\hline & & $\begin{array}{l}\mathrm{L}_{1} \\
\text { water } \\
\mathrm{n}=6\end{array}$ & $\begin{array}{l}\mathrm{L}_{1} \\
\text { Soil } \\
\mathrm{n}=7\end{array}$ & $\begin{array}{l}\mathrm{L}_{1} \\
\text { Fish } \\
\mathrm{n}=18\end{array}$ & $\begin{array}{l}\mathrm{L}_{1} \\
\text { Clam } \\
\mathrm{n}=12\end{array}$ & $\begin{array}{l}F_{1} \text { Soil } \\
n=8\end{array}$ & $\begin{array}{l}F_{1} \\
\text { Water } \\
n=6\end{array}$ & $\begin{array}{l}F_{1} \\
\text { Fish } \\
n=12\end{array}$ & $\begin{array}{l}F_{2} \text { Soil } \\
n=10\end{array}$ & $\begin{array}{l}\mathbf{F}_{2} \\
\text { Water } \\
\mathbf{n}=\mathbf{1 2}\end{array}$ & $\begin{array}{l}F_{2} \\
\text { Fish } \\
n=14\end{array}$ \\
\hline & MAR\% & 83 & 100 & 94.44 & 100 & 100 & 87 & 83 & 100 & 100 & 93 \\
\hline & Sensitive\% & 16 & 0 & 5.55 & 0 & 0 & 12.5 & 16.66 & 0 & 0 & 7.1 \\
\hline $\begin{array}{l}\text { Antibiotic } \\
\text { Used }\end{array}$ & Class of antibiotic & \multicolumn{10}{|c|}{ Individual antibiotic resistance profile (\%). } \\
\hline AMP & B-lactamase. & 83.33 & 85.71 & 83.33 & 91.66 & 75.00 & 66.50 & 83.33 & 80.00 & 75.00 & 83.65 \\
\hline $\mathbf{A K}$ & Aminoglycoside & 58.33 & 71.42 & 72.22 & 83.33 & 87.50 & 50.00 & 75.00 & 70.00 & 66.66 & 78.57 \\
\hline AZM & Macrolides & 41.66 & 85.71 & 72.22 & 75.00 & 87.50 & 66.50 & 66.50 & 70.00 & 75.00 & 75.56 \\
\hline CB & Penicillins & 66.66 & 71.42 & 77.77 & 83.33 & 75.00 & 66.50 & 83.33 & 80.00 & 75.00 & 78.57 \\
\hline $\mathbf{C}$ & Chloramphenicol & 66.66 & 71.42 & 66.66 & 75.00 & 75.00 & 66.66 & 75.00 & 70.00 & 58.33 & 64.28 \\
\hline CIP & Fluoroquinolones & 66.66 & 57.14 & 55.55 & 66.66 & 87.50 & 50.00 & 66.66 & 60.00 & 58.33 & 64.28 \\
\hline CPM & Cephalosporin & 91.66 & 85.71 & 77.77 & 91.66 & 87.50 & 83.33 & 100 & 80.00 & 75.00 & 85.71 \\
\hline $\mathbf{E}$ & Macrolides & 58.33 & 57.14 & 66.66 & 83.33 & 62.50 & 83.33 & 75.00 & 70.00 & 66.66 & 64.28 \\
\hline GEN & Aminoglycoside & 50.00 & 57.14 & 55.55 & 75.00 & 50.00 & 66.50 & 58.50 & 70.00 & 58.33 & 57.14 \\
\hline $\mathbf{K}$ & Aminoglycoside & 66.66 & 71.42 & 66.66 & 75.00 & 62.50 & 66.66 & 75.00 & 80.00 & 75.00 & 64.28 \\
\hline MET & Penicillins & 91.66 & 85.71 & 100 & 100 & 87.50 & 83.33 & 91.66 & 100 & 100 & 100 \\
\hline NA & Fluoroquinolones & 83.33 & 85.71 & 77.77 & 83.33 & 75.00 & 83.33 & 91.66 & 90.00 & 83.33 & 85.71 \\
\hline $\mathbf{P}$ & Penicillins & 100 & 100 & 100 & 100 & 100 & 100 & 100 & 100 & 100 & 100 \\
\hline PB & Polypeptides & 83.33 & 100 & 72.22 & 75.00 & 100 & 83.33 & 83.33 & 80 & 75.00 & 78.57 \\
\hline $\mathbf{S}$ & Aminoglycoside & 83.33 & 85.71 & 77.77 & 83.33 & 75.00 & 66.66 & 75.00 & 70.00 & 66.66 & 71.42 \\
\hline TE & Tetracyclines & 58.33 & 57.14 & 55.55 & 75.00 & 75.00 & 66.66 & 75.00 & 70.00 & 58.33 & 64.28 \\
\hline TR & Sulphonamides & 83.33 & 71.42 & 66.66 & 66.66 & 75.00 & 83.33 & 83.33 & 80.00 & 66.66 & 78.57 \\
\hline VA & Glycopeptide & 91.66 & 100 & 94.44 & 100 & 100 & 100 & 83.33 & 100 & 91.66 & 100 \\
\hline
\end{tabular}


Fig.1 Different sampling sites of the study

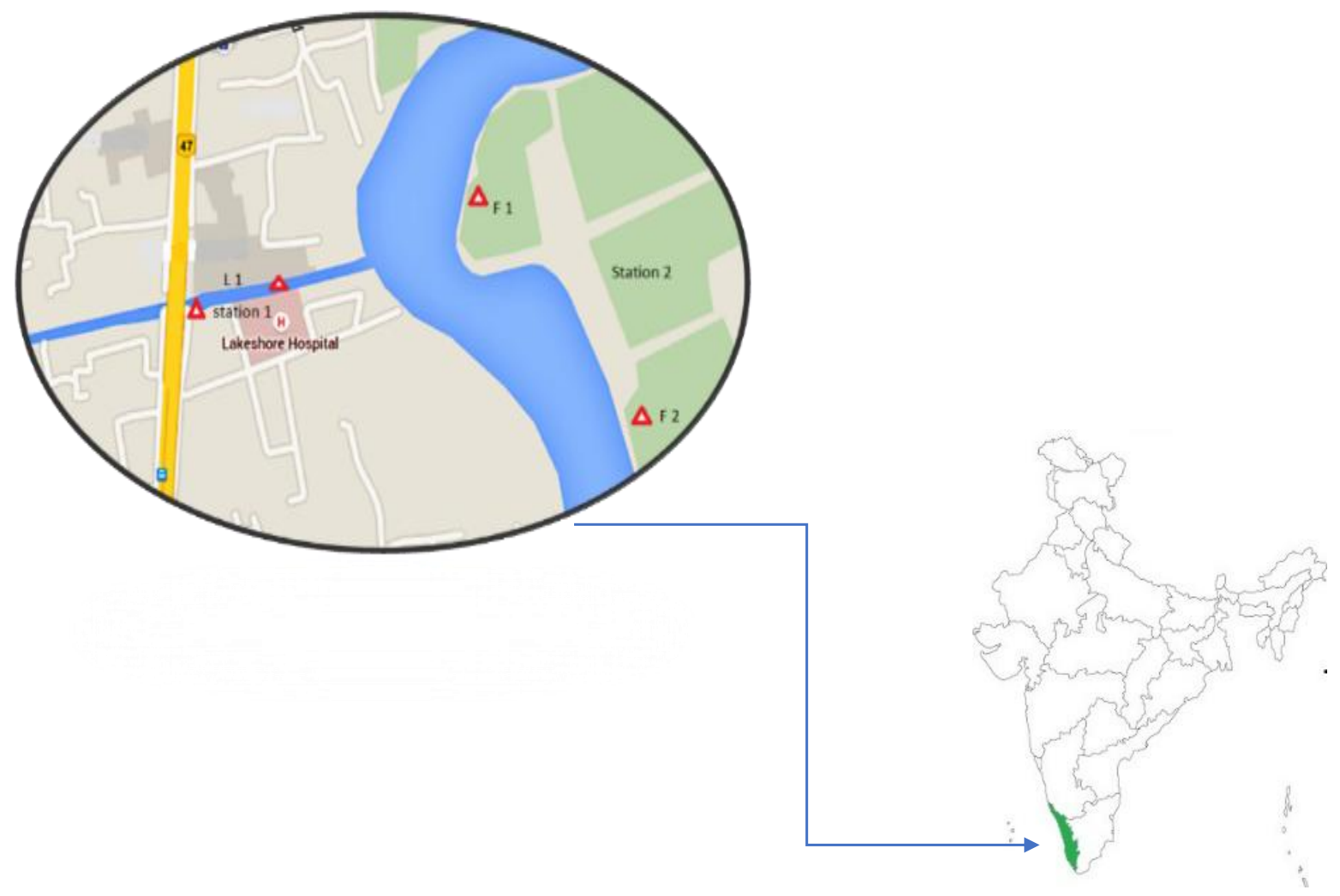

Fig.2 The population of bacteria in different classes exhibited in the study

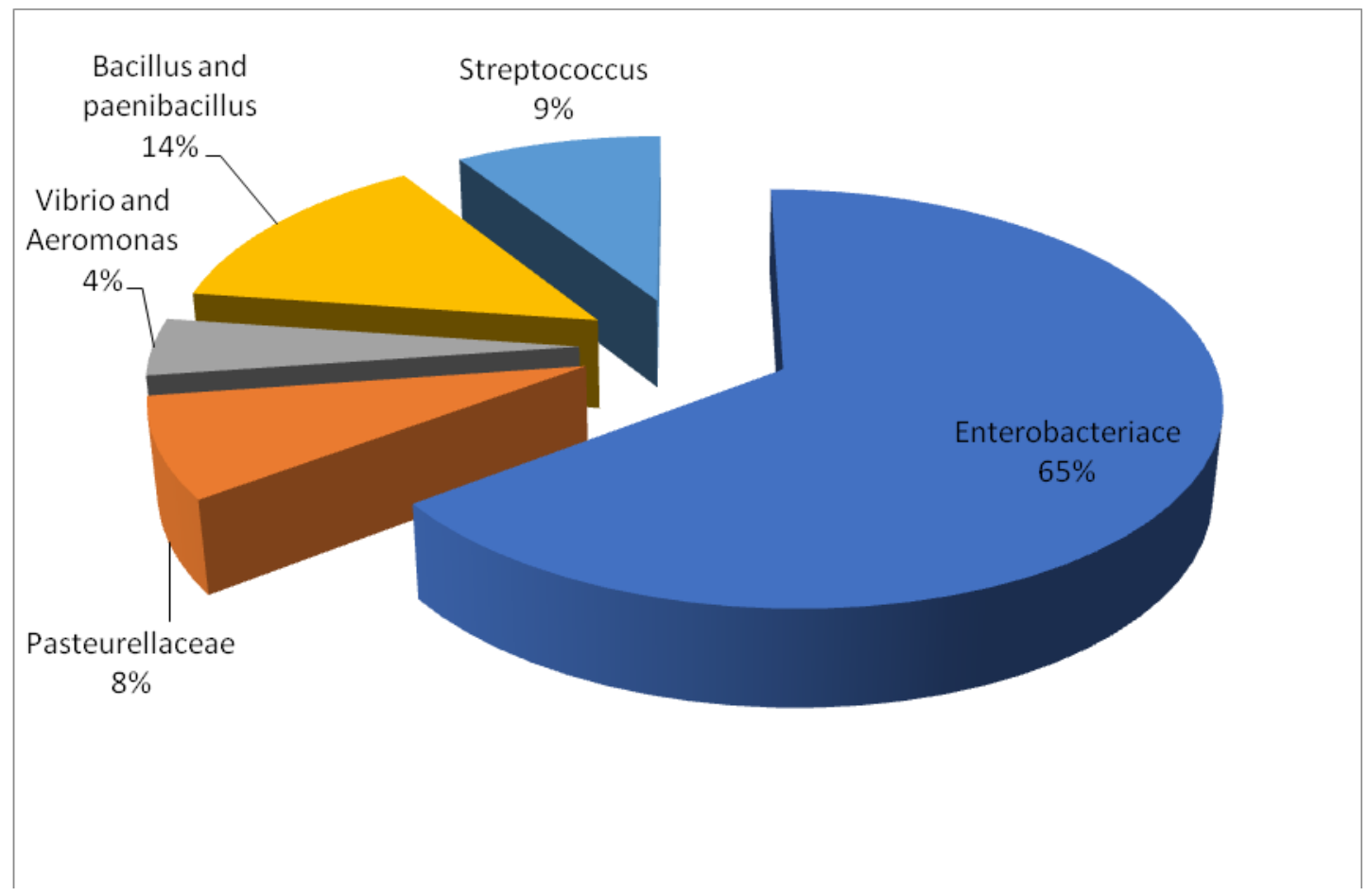


Fig.3 MAR \% of different samples

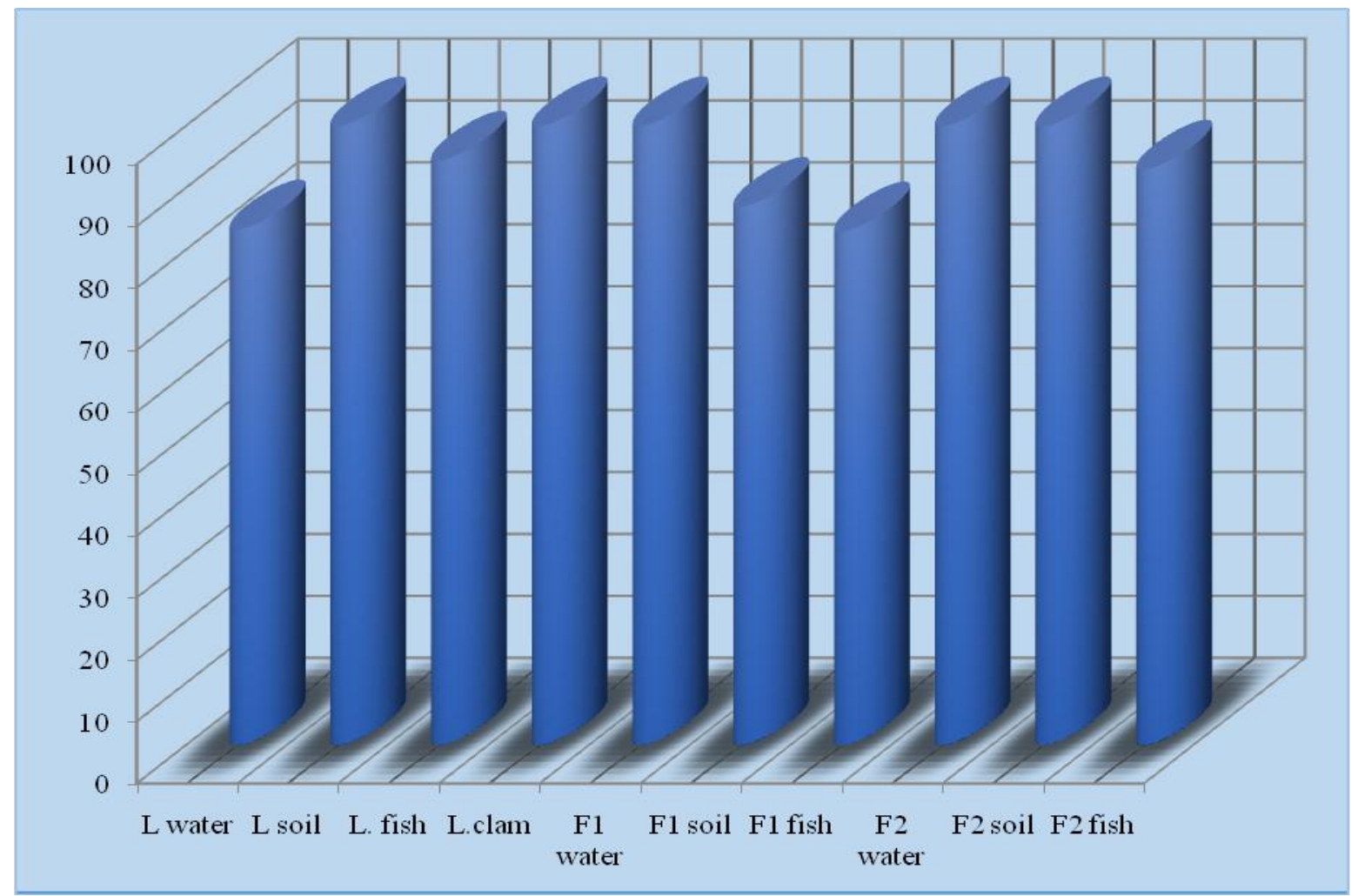

Fig.4 MAR \% of total isolates irrespective of all samples. Note: $\mathrm{X}$ axis denotes samples and y axis denotes MAR\%

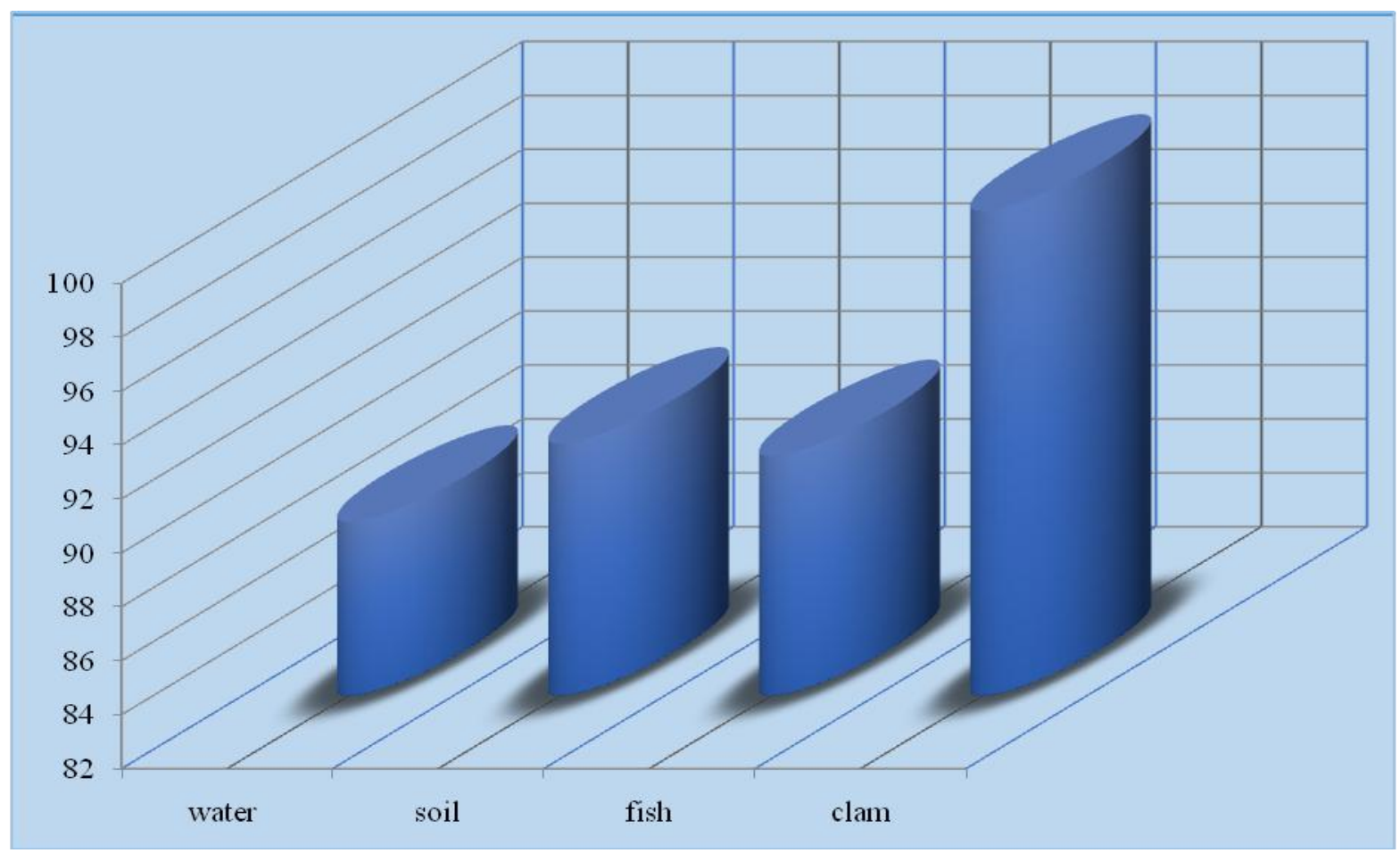


Fig.5 MAR\% exhibited by various bacterial classes

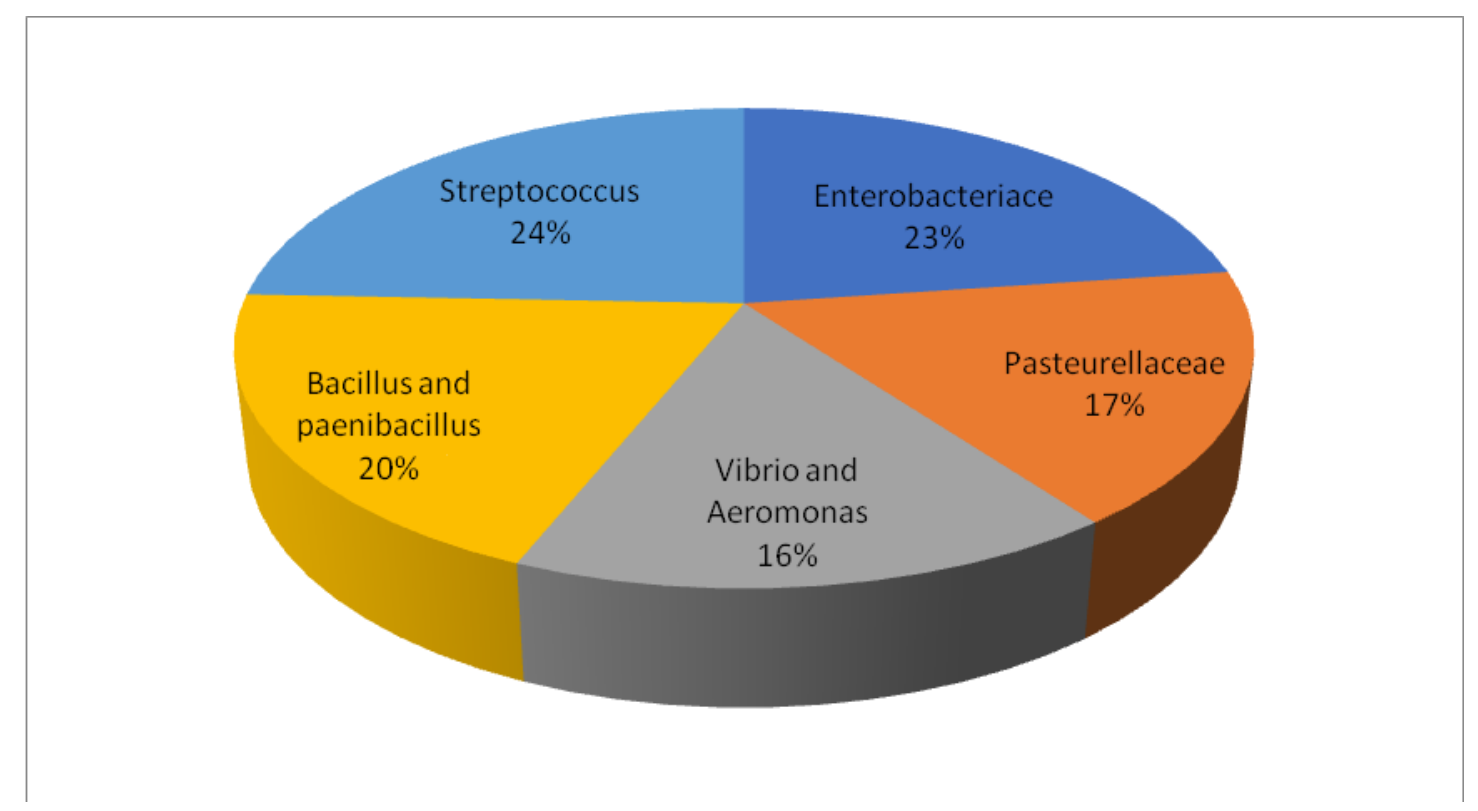

\section{MAR index}

The multiple antibiotic resistances (MAR) pattern of isolates was calculated and it was observed that all the isolates showed MAR index of more than 0.2, indicating multiple resistance to antibiotics. A MAR index of 0.2 or more is said to have originated from high risk sources of contamination like human, commercial poultry farms, swine, dairy cattle and domestic sewage where antibiotics are very often used. MAR index value less than or equal to 0.2 considered as the origination of strain from animals in which antibiotics are seldom or never used (Krumperman, 1985).

In the present study the strains like Klebsiella pneumoniae, Klebsiella oxytoca, Bacillus circulans, Streptococcus equi, Bacillus spp, Edwarsiella spp, Flavobacterium breve and Photobacterium spp etc, which were almost isolated from all the samples showed similar kind of MAR index, which was on the higher range. Higher value of MAR index means that the microbes were mainly originated from human contamination like hospital discharge and were disseminating its resistance potential to other aquatic microbes in the aquatic environment. Similar kind of resistance observed from the two stations implies that the microbes is either acquiring or disseminating its resistance potential at an alarming rate which is a global threat (Fig. 5).

\section{Statistical analysis}

Analysis of variance carried out for comparing the antibiotic resistance index (ARI) in both the station. During the analysis it was observed that there was no significant difference $(P>0.01)$ among the antibiotic resistance index in the seven samples among the two stations. Since the water from station1 served as the source water for the aquaculture farm (station 2), the isolates would have spread and reached other areas. So we can conclude saying that the resistance from station 1 is equally transmitted to the other stations i.e., station 2.

Similarly ANOVA was also carried out for comparing the MAR\% among the antibiotics as well as among the sampling sites. During the analysis we found out that there was 
significant difference in MAR\% among the antibiotics as well as among sampling sites $(\mathrm{P}<0.01)$.

The wide spread of antibiotic resistance in the global ecosystem has become a major public health distress. High incidence of resistant bacteria in response to antibiotic usage have been reported in coastal maricultural areas (Herwig et al., 1997; Manjusha et al., 2005 and 2011). Large scale aquaculture has been associated with environment issues worldwide as a consequence of accelerated development and high stocking density. Not surprisingly, intensification of aquaculture activities has seen a surge in the use of chemicals and antibiotics either to prevent or treat diseases. Similarly, the increase in antibiotic resistance within clinical bacterial isolates is undermining the efforts of antibiotics used in the treatment of infectious bacterial diseases. Intensive use of antibiotic in clinical and agriculture settings has been suggested to promote an increase in antibiotic resistant bacterial populations (Aminov, 2009). In the present study we found that a large number of different isolates showed a high degree of resistance to different antibiotics used in the study. It also has been observed that same isolates from different stations showed different antibiotic resistance pattern.

The present study revealed that most of the bacteria showed high resistance to almost all the antibiotics tested. The highest ARI was calculated for Enterobacteriace and Streptococcus. It may be because a maximum number of isolates belonged to these two groups and all these isolates showed resistance against multiple number of antibiotics. The observations were also quite similar with findings of Patra et al., (2009), who investigated the occurrence and distribution of resistant bacteria in the coastal waters of Orissa. Similar results was also reported from earlier by Manjusha et al., (2005), who studied the occurrence of multiple antibiotic resistance isolated from vibrio from coastal and brackish waters of Kerala. In the present study, Klebsiella pneumoniae and Klebsiella oxytoca were observed to be highly resistant bacteria among all the isolates. The increase in the concentration of multi drug resistant bacteria in the aquatic environment may create selective pressure on natural bacterial strains which leads them to acquire the resistance from the resistant bacterial plasmid. (Osman et al., 2007). In the present study statistically, it was observed that there was no significant difference among the antibiotic resistance index between the two sampling sites in the stations, which may be the indications of the above-mentioned statement.

Of the total isolates from 10 different samples of the study area $45.71 \%$ were resistant against more than 10 antibiotics, $41.90 \%$ were resistant against 4 to 10 antibiotics, $5.71 \%$ were resistant against three antibiotics and $6.66 \%$ were susceptible to all the antibiotics. This result may be the indication that majority of bacteria in aquatic environment are developing resistance against commonly used antibiotics in aquatic environment.

Highest incidence of antibiotic resistance was recorded from penicillin, methicillin, vancomycin, ampicillin, nalidixic acid and cefepime. These antibiotics are commonly used to prevent disease in human beings. The result of the present study clearly indicates that terrestrial bacteria entering into water bodies with antibiotic resistant plasmids might have contributed to the prevalence of the resistance genes in the aquatic environment. A similar observation was made by Chandrasekaran et al., (1998) who reported the presence of antibiotic resistant genes. The isolates collected from different sampling sites showed similar resistance 
pattern. On statistical analysis, it was observed that there was significant difference in the resistance of the antibiotics irrespective of sampling sites, which is shown in table 3 . A high degree of resistance towards methicillin, vancomycin and penicillin has been displayed by the isolates. Maximum resistance was shown by the isolates from fish and clam samples from the study area of station one. They showed $100 \%$ resistance to the above-mentioned antibiotics. Schmidt and Bruun (2001), Akinbowale and Peng (2007) and Sredharan et al., (2012) have also observed high tetracycline resistance in Aeromonas spp isolated from aquaculture farms.

In the present study it is found that MAR value was slightly higher in station 1 when compared to station 2. Within station 1 the value was higher in clam and fishes. Bacteria like Klebsiella spp and Streptococcus which showed high resistance to different antibiotics like penicillin, methicillin and vancomycin was isolated from the fish sample obtained from the study area.

Presence of antibiotic resistant bacteria in a given environment may be an indication that an area is contaminated with antibiotics (Herwig, 1997). The high levels of antibiotic resistance prevalent among bacteria in the farms suggest that the source water is contaminated with antibiotics. This clearly indicates that the discharge from the hospital reaches the public water body and is the main source of contamination. Antibiotic resistance revealed by bacteria which are normally present in the aquaculture environment and sensitive to most antibiotics suggest the transfer of resistance genes from clinical isolates such as Klebsiella, Streptococcus, etc. obtained in the present study.

The outcomes of the present study distinctly show the occurrence and the spread of AMR from terrestrial environment to aquatic environment. Since the spread of AMR genes can occur very easily between bacteria as shown in the present study, the implication in the terms of the risk to human health is truly alarming. Use of antibiotics and spread of AMR genes in the aquatic environment will distinctly affect aquaculture production, with farmers having to use higher and higher doses of antibiotics to control bacterial infections. This will ultimately affect the health of consumers too. The mounting problem or hazard posed to human health can be checked only by educating or creating awareness among the public about the impending risks. Use of antibiotics importantly, government has to issue and implement very strict guidelines to check indiscriminate use of antibiotics and ensure proper treatment of wastes before discharge to the environment.

\section{Acknowledgement}

The authors would like to kindly express their appreciation for the support rendered by Centre of Aquatic Animal Health Management, School of Aquaculture and Biotechnology, Kerala University of Fisheries and Ocean Studies to carry out the research work.

\section{Declaration of interest}

All authors report no conflict of interest related with this manuscript.

\section{References}

Akinbowale, O. L., H. Peng, (2007). Diversity of tetracycline resistance genes in bacteria from aquaculture sources in Australia. Journal of applied microbiology 103(5): 2016-2025.

Aminov, R. I. (2009). The role of antibiotics and antibiotic resistance in nature. Environmental microbiology 11(12): 
2970-2988.

Bauer, A.W., Kirby, W.M.M., Serris, J.C. and Turck, M. (1966). Antibiotic susceptibility testing by a standardized single disc method. American Journal of Clinical Pathology 45: 493-496

Chandrasekaran, S., B. Venkatesh and D Lalitthakumari, (1998). Transfer and expression of a multiple antibiotic resistance plasmid in marine bacteria. Current Microbiology 37(5): 347-351.

Grigorakis, K. and G. Rigos (2011). Aquaculture effects on environmental and public welfare-the case of Mediterranean mariculture. Chemosphere 85(6): 899-919.

Herwig, R. P., J. P. Gray, and D. P. Weston. 1997. Antibacterial resistant bacteria in surficial sediments near salmon netcage farms in Puget Sound, Washington. Aquaculture 149:263-283.

Hinton, M. and A. Linton (1983). Antibacterial drug resistance among Escherichia coli isolated from calves fed on a milk substitute diet. Veterinary Record 112(24): 567-568.

Krumperman, L. (1985). Effect of Pbemedication. Urology 8.

Manjusha, G., K. Rajathi, et al., (2011). Antioxidant Potential and Antimicrobial activity of Andrographis paniculata and Tinospora cordifolia against pathogenic organisms. Journal of Pharmacy Research 4(2).

Osman BirolOzgumus, ElifCelik-E Sevim, SengulAlpay- Karaoglu, CemalSandalli and aliSevim (2007) Molecular
Charaterisation of antibiotics Escherichia coli strains isolated from tap water and spring water in a coastal Region in Turkey. Journal of Microbiology, vol 45 No; 5, p-379-387.

Patra, J., A. Patra, (2009). Antimicrobial activity of organic solvent extracts of three marine macroalgae from Chilika Lake, Orissa, India. Malaysian Journal of Microbiology 5(2): 128-131

Rawn, D. F., K. Breakell, (2009). Persistent organic pollutants in fish oil supplements on the Canadian market: polychlorinated biphenyls and organochlorine insecticides. Journal of food science 74(1): T14-T19.

Rigos, G., K. Bitchava, (2010). Antibacterial drugs in products originating from aquaculture: assessing the risks to public welfare. Mediterranean marine science 11(1): 33-42.

Schmidt, A. S., M. S. Bruun, (2001). Incidence, distribution, and spread of tetracycline resistance determinants and integron-associated antibiotic resistance genes among motile aeromonads from a fish farming environment. Applied and environmental microbiology 67(12): 5675-5682.

Sreedharan, K., R. Philip and ISB Singh (2012). Virulence potential and antibiotic susceptibility pattern of motile aeromonads associated with freshwater ornamental fish culture systems: a possible threat to public health. Brazilian Journal of Microbiology 43(2): 754-765.

\section{How to cite this article:}

Hemanta Pokhrel, Sangipran Baishya, Bipul Phukan, Devika Pillai and Mohd Ashraf Rather. 2018. Occurrence and Distribution of Multiple Antibiotic Resistance Bacteria of Public Health Significance in Backwaters and Aquaculture Farm. Int.J.Curr.Microbiol.App.Sci. 7(02): 975987. doi: https://doi.org/10.20546/ijcmas.2018.702.121 